Ольга Исупова, Валерия Уткина

\title{
МОЛОДЫЕ ЖЕНЩИНЫ В ОРГАНАХ ГОСУДАРСТВЕННОГО УПРАВЛЕНИЯ РОССИИ: ФАКТОРЫ, ОПРЕДЕЛЯЮЩИЕ КАРЬЕРНЫЕ ТРАЕКТОРИИ
}

\begin{abstract}
Статья посвящена изучению позиции женщин в органах государственного управления Российской Федерации. Анализируются 32 полуструктурированных интервью с молодыми женщинами, имеющими опыт работы на госслужбе. Интервью подвергнуты анализу с целью выявления основных тем, важных для этой группы женщин в связи с особенностями их деятельности. Изучаются их представления о том, является ли работа в органах государственной власти «подходящей» для женщин, и почему они в этой отрасли присутсвуют на всех должностях, кроме самых высоких. С одной стороны, мы выявили устойчивый стереотип в отношении разделения сфер труда на мужскую (власть, ответственность) и женскую (работа помощника, организатора или более творческая, но, скорее, индивидуальная - например, аналитик). С другой - отмечаются противоположные взгляды, характеризующие изучаемую группу женщин как обладающую высокой самооценкой и стремящуюся к «экспертной» самореализации. Таким образом, согласно оценкам наших собеседниц, женщины во властных структурах, как правило, не стремятся к высшим ступеням власти. Тем не менее их профессиональные стремления нацелены на самореализацию в карьере «специалиста в своей области»: рутинный труд их не удовлетворяет, проблематичной является низкая зарплата, женщины стремятся различными способами (должностной рост, длительные рабочие часы, переход в другую сферу деятельности) повысить зарплату. Это связано с их высоким уровнем образования,
\end{abstract}

Ольга Генриховна Исупова - PhD in Sociology, доцент, старший научный сотрудник, Институт демографии, Центр демографических исследований, НИУ ВШЭ, Москва, Россия. Электронная почта: oisupova@hse.ru

Валерия Владимировна Уткина - старший преподаватель, факультет социальных наук, департамент государственного и муниципального управления НИУ ВШЭ, Москва, Россия. Электронная почта: utkinavv@hse.ru 
обуславливающего определенные притязания и самоуважение. Отсутствие стремления к высоким должностям у большинства связывается с тем, что для женщины продвижение по службе часто ассоциируется с невозможностью «личной жизни», которая требует времени и сил, а также баланса между домом и работой.

Ключевые слова: госслужба, женщины в управлении, гендерные исследования, гендерные предубеждения второго поколения

DOI: $10.17323 / 727-0634-2018-16-3-473-486$

Исторически государственная служба сложилась как «мужское» занятие. В XX в. в разных странах женщины постепенно начали осваивать профессию чиновника, что объясняется, с одной стороны, их массовым выходом на рынок труда, а с другой - ростом социальных функций государства (Кашина 2009; Тартаковская 2001, 2015). В последние десятилетия в России, согласно статистике Росстата (2016), идет процесс феминизации государственной гражданской службы (здесь и далее мы будем использовать понятие «госслужба», включающее только представителей государственной гражданской службы). Под феминизацией мы понимаем постепенное увеличение численности женщин в кадровом составе госслужбы. Так, доля женщин на госслужбе в 2016 г. составила $72 \%$, мужчин - $28 \%$, и такое распределение неизменно с 1999 г. Женщины-госслужащие численно преобладают, прежде всего, среди специалистов, что свидетельствует о возложении на госслужбе властных полномочий и высшей ответственности на мужчин, а вспомогательной организаторской и аналитической работы - на женщин.

Целью статьи является изучение факторов, детерминирующих «низкие» карьерные траектории женщин в государственном управлении в современной России. Мы сосредоточили внимание на представлениях о карьере женщин на госслужбе, а также на структурных барьерах, ограничивающих их карьерное продвижение. Мы подробно рассматриваем как индивидуальные, так и внешние факторы, которые могут определять текущее положение дел в области гендерного распределения труда на госслужбе в России.

\section{Карьера женщины на госслужбе: что способствует и что мешает}

Исследования показывают, что несмотря на большое число антидискриминационных законов в области государственной службы, сохраняется разрыв в заработной плате между женщинами и мужчинами (Bearfield 2009; Hsieh, Winslow 2006). Кроме «стеклянного потолка», т. е. совокупности различных социальных факторов, препятствующих тому, чтобы женщины занимали более высокие, в том числе руководящие, должности, существуют также и «стеклянные стены», обуславливающие их сегрегацию 
в отдельных областях управления: социальной и культурной сфер, во многих странах образовании и здравоохранении, в то время как наименее «женскими» остаются силовые структуры и транспорт (Batista Medina 2015). Распространенные стереотипы связывают эти тенденции с наличием у женщин особых черт (доброты, уступчивости, склонности согласовывать интересы), отличных от «мужских» (жесткости, твердости, смелости при принятии решений). Как показывают исследователи, эти стереотипы разделяются значительным числом госслужащих обоих полов, в том числе, при приеме на работу и принятии решений о продвижении по службе (Guy, Schumacher 2009).

Ученые обращают внимание на гендерные предрассудки первого поколения, связывая их с открытой и целенаправленной дискриминацией или исключением женщин (Ibarra et al. 2011). Позднее возникла концепция гендерных предрассудков второго поколения, характеризующихся неосознанной дискриминацией. Предубеждения второго поколения часто разделяют и сами женщины. Как правило, они не планируют продвижения по карьерной лестнице, а если планируют, то сталкиваются с ситуацией, когда их поведение рассматривается коллегами либо как слишком «женское» и неподходящее для лидера, либо как чрезмерно жесткое и «неженское» (Ibarra et al. 2010, 2011).

Мужское единство имеет огромное значение для исключения женщин из формальных и особенно неформальных коллективных практик, связанных с успешным продвижением в профессии. Обязанности распределяются между людьми разного пола в соответствии с признаками и содержанием приписываемыми самой работе. Характер и тип рабочего места также часто определяются исходя из ожиданий, как мужчины или женщины будут эту работу исполнять (Тартаковская 2001:91). С точки зрения Рейвин Коннелл (2015), любые рабочие практики производятся в соответствии с конкретными социальными условиями, частью которых является гендерное разделение труда. Коннелл предлагает термин «гендерный порядок» для описания совокупности институтов и практик, организующих социальные различия полов в конкретном обществе, в частности, в сфере трудовых отношений, одновременно являющихся частью гендерно-структурированной системы производства, потребления и распределения.

Некоторые исследователи считают, что выделение «женских» сфер внутри оплачиваемого труда в различных секторах экономики характерно для России (Мальцева, Рощин 2007:25). Представления управленцев относительно «естественных» мужских и женских задач по-прежнему подвержены гендерным стереотипам (см. напр.: Ахмадеева 2011). Хотя нормативный дискурс часто гендерно нейтрален, гендерная дифференциация, т.е. распределение сфер деятельности и статусов в соответствии с «мужскими» и «женскими» ролями, осуществляется посредством обращения к таким конструктам, как «стили управления», «руководящий/исполнительский 
труд», «рациональность/эмоциональность». Так, некоторые стили, эмоциональность, склонность к выполнению исполнительских функций приписываются чаще женщинам, обратное - мужчинам. При этом специфика постсоветского гендерного разделения труда определяется советским гендерным контрактом «работающая мать», который предполагает совмещение домашних обязанностей с оплачиваемой занятостью (Здравомыслова, Темкина 2002). Постсоветское развитие привело к значительной вариативности такого контракта, вплоть до того, что элемент материнства и/или работы может вообще отсутствовать в конкретных случаях. Однако женщина рефлексирует по поводу «временно отсутствующей» части контракта, и подстраивает свое поведение под социальные требования, не позволяющие погружаться только в одну сферу труда - домашнюю или рабочую (Исупова 2015).

Многие сферы труда, в частности госслужба, в рамках постсоветского контракта предполагают у большинства работников ориентацию на карьерный рост. Под карьерой мы понимаем внутриорганизационную (должностную) карьеру, заключающуюся в изменении должностного статуса и роли в организации (Климова, Терехов 2013), т.е. вертикальную внутриорганизационную карьеру. В исследовании Аллы Чириковой (2013) выделяются три модели продвижения женщин на госслужбе: (1) постепенный рост в связи с ростом профессионализма; (2) «парашютирование» - привлечение кандидаток извне, часто это продвижение с помощью связей, знакомств; (3) «наследование», когда политическая карьера «передается» внутри семьи. Чирикова приходит к выводу, что процесс попадания женщин во властные структуры, особенно в России, достаточно случаен, а карьерное продвижение является результатом не целенаправленных усилий самих женщин, а только решения руководителя (чаще всего мужчины). Случается, что женщины делают карьеру, не претендуя на высокие должности. Таким образом, важно выяснить, что влияет на концентрацию женщин на госслужбе (с их собственной точки зрения) на невысоких должностях: структурные ограничения или представления сотрудников о гендерных особенностях мужчин и женщин как работников - то есть гендерные стереотипы первого или второго поколения, и как именно проявляется воздействие ограничений.

\section{Методология исследования}

В 2016 г. проведено 32 полуструктурированных интервью с женщинами, занятыми на государственной гражданской службе в органах исполнительной власти федерального значения, располагающихся на территории г. Москвы. Мы интервьюировали тех, кто проработал не менее двух лет в госорганах, т.к. это минимальный срок для возможного повышения в соответствии с действующим законодательством (Федеральный закон 2004). Для лучшей сопоставимости данных мы соблюдали критерий 
принадлежности участниц к одному поколению, было установлено возрастное ограничение в 25-35 лет.

Методика построения выборки сочетала принцип снежного кома (что оправдано при исследовании государственных чиновников, так как в целом это поле закрыто и труднодоступно) и элементы квотной выборки. Критериями квотирования являлось стремление охватить сотрудниц как можно большего числа госструктур. Должности опрошенных включали от начальника отдела в департаменте федерального министерства до специалиста в федеральном агентстве. Но должность, как и классный чин, не была критерием квотирования, одной из наших задач было рассмотрение того, на каких должностях оказываются выпускницы вузов через два года работы на госслужбе. Обработка транскриптов интервью проводилась с помощью открытого и осевого кодирования (Lindlof, Taylor 2002: 45). Далее следовала интерпретация смысловых конструкций, выявленных в ходе кодирования.

\section{Причины работы женщин на государственной службе}

Первоначальная мотивация к получению профессионального образования в области госуправления примерно в третьей части изученной совокупности связана с «механизмом наследования» (Чирикова 2013): в семье кто-то занимался государственным управлением, либо существовали традиции службы государству, например, военной:

У меня отец военный, то есть тоже госслужба... ну, у меня бабушка депутат высшей [региональной] областной думы, и мне казалось, что если я пойду на госслужбу, то я стану депутатом... Казалось, что это очень круто (главный специалист-эксперт, Федеральное агентство научных организаций).

Это позволяет предполагать, что госслужбу можно отнести к династийным профессиям - таким как врачи, профессиональные спортсмены, или военные. Династийность определяет устойчивое воспроизводство культурных паттернов, в том числе и гендерных, в рамках профессии (Ткач 2007). Однако мотивация поступать на госслужбу у женщин связана и с поиском профессии в междисциплинарной области с гуманитарным профилем. По мере развития карьеры, мотивация, связанная с гуманитарными науками как частью персональной идентификации или семейной традиции, сочетается с профессиональным опытом и формирует отношение к собственной профессии как призванию (Вебер 1990: 644-706). Тем не менее другой сценарий трудоустройства на госслужбу включает случайность:

...я не собиралась идти на госслужбу, но так получилось, других достойных нормальных вариантов не было... взяли на самую маленькую должность... думала, что это временно, но вот уже шесть лет там работаю, понравилось (консультант, Федеральная налоговая служба). 
В некоторых случаях привлекательность госслужбы связана с образом «женской» работы, то есть работы с социальными гарантиями, важными для женщин: льготы по рождению ребенка в бизнесе не так распространены, как в госсекторе:

Для девушки государственная служба - это же гарантии. Пусть она в зарплате, наверное, проигрывает, по сравнению с частными структурами. Но особенно для девушки, декреты, там, выплаты, сохранение места - это все довольно важно, собственно, отчасти поэтому мой выбор пал на госслужбу (консультант, Аппарат Государственной Думы ФС РФ).

Итак, если говорить о выборе госслужбы как занятия, доминирующие мотивации связаны с семейными традициями, общегуманитарными образовательными предпочтениями или социальными гарантиями. Три типа мотивации не всегда существуют изолированно, часто выбор определяется на их пересечении.

\section{Особенности карьерного продвижения женщин на госслужбе}

Как отмечалось выше, одна из особенностей положения женщин на госслужбе - высокая концентрация на низших и средних ступенях карьерной лестницы, а также, соответственно, крайне редкое присутствие на верхних. Какие факторы определяют ситуацию? Анализ интервью позволил выявить возможные объяснения: дискриминация; эссенциалистские представления о мужских и женских функциях; конформизм, отказ от сопротивления, предпочтение «приспособленческой» стратегии; баланс рабочего и нерабочего времени.

Дискриминационные практики. Некоторые интервьюируемые отмечают, что сталкивались если не с дискриминацией (это слово не любят употреблять, оно ассоциируется с нежелательным для них открытым сопротивлением - подробнее ниже), то с некоторым специфическим отношением к женщинам:

В России глобальные есть проблемы с положением женщин на работе... ну, женщина - это женщина. Сиди, женщина... У меня был такой момент при собеседовании, мне сказали... вы - женщина, вы уйдете [в декрет], какой смысл вас нанимать на работу (главный специалист-эксперт, Министерство экономического развития).

Таким образом, работодатель ожидает, что женщина обязательно родит, следовательно, кто-то должен заменять ее на работе, пока она будет в отпуске по уходу за ребенком. Более того, фраза «сиди, женщина» демонстрирует негативно-эмоциональное отношение к работнику, который должен «знать свое место». Подобное отношение иногда преодолевается по мере роста профессионального капитала. 
Некоторые информантки относят дискриминацию к определенным этапам карьерного продвижения: «[Это работает], начиная от замминистра» (зам. начальника отдела, Министерство труда и социальной защиты). Такая ситуация свидетельствует о некоторой схожести норм бюрократической иерархии в организациях госслужбы и патриархатной структуры в целом.

Эссенциалистские представления о женщинах на работе. Понятие «стиль управления» часто используется в эссенциалистских суждениях о том, что «более эмоциональная» женщина «по своей природе» руководит хуже, чем «от природы рациональный» мужчина. Встречались такие трактовки положения женщин на госслужбе и среди наших информанток:

У мужчин нет капризов, у мужчин нет слез... нежелания работать больше у женщин... Мужчины более склонны к абстрактному мышлению, нежели женщины, женщины, это такой предметный, приземленный [стиль мышления] (руководитель отдела, Министерство юстиции).

Негативные примеры чрезмерно «эмоционального» поведения женщин-начальниц в наших интервью встречаются чаще, чем упоминания о «хороших» начальницах, а иногда интервьюируемые утверждают, что лучше работать с «рациональным» начальником-мужчиной:

Если женщина эмоциональна... то ОЧЕНЬ сложно работать... вспыльчивость, истерики... бросается чем-нибудь, она об этом быстро забывает, но у всех остальных остается осадок (руководитель отдела, Министерство юстиции).

Случаи удачной самореализации под началом женщины тоже описываются в интервью, но объяснения им даются в эссенциалистской логике, т.е. основаны на разделении природы «мужского» и «женского». Информантки отмечают, что «хорошая начальница» - это человек с «мужским характером», или переносят в трудовую сферу «материнские преимущества»: «хорошая начальница» готова быть на работе двадцать четыре часа в сутки и способна по-матерински сплачивать и мотивировать свою команду:

[Прежняя начальница] активно принимала участие в различных мероприятиях, мы практически с ней были везде, и вечером, и ночью, собственно, всегда, когда мы ей нужны, мы были под боком... погруженность в работу, это действительно захватывало, драйв, адреналин, потому что когда еще плюс сам руководитель умный, энергичный и душевный тоже человек, то это все подкупает, зажигает, и вот она идет вперед и ты за ней (консультант, Росимущество).

Мозаичное сочетание «мужского» и «женского» в стиле руководства «хорошей начальницы» продолжается в сочетании способности быть, с одной стороны, «по-женски» гибкой, понимающей, снисходительной, и «по-мужски» харизматичной, способной вести за собой - с другой. 
Материнство ассоциируется с адаптивностью к ролям, связанным с ответственностью, умением быстро принимать решения и учитывать индивидуальные особенности подчиненных-«детей», а мужские качества ассоциируются с целеустремленностью, властностью на формальном уровне. Наилучшей иллюстрацией эссенциалистской логики будет цитата из интервью:

Мужчины более упрямые, более самодуры, менее гибкие, менее адаптивные, женщины за счет своих каких-то природных особенностей, того, что она предназначена природой, как мать, у нее адаптивные свойства более сильно развиты (консультант, Аппарат мэра).

Информантки, которые сами являются начальницами отделов, отмечают готовность и умение войти в положение подчиненных, «справедливо» распределить работу, подчеркивая, прежде всего, свои «материнские» качества:

Я не такой начальник, который просто расписывает почту и потом собирает ее обратно, я часть работы оставляю себе, самую ответственную и сложную. Делегирую не слишком сложные нормативные акты... специфика у всех разная, разная усидчивость опять же, загрузка, дом (руководитель отдела, Министерство юстиции).

Приспособительные стратегии. В целом информантки считают, что госслужба устроена так, что они как женщины практически не могут рассчитывать продвинуться «на самый верх»:

Верхнеуровневые руководители, как президент, мэр, губернатор, [это] для женщин, на мой взгляд, практически совсем недоступно... замом ты можешь быть... (консультант, Аппарат мэра).

При этом многие осознанно отрицают саму возможность продвижения по службе для себя, объясняя, что высокие должности лишают женщину «личной жизни»:

Чем выше должность, тем больше ответственность, тем меньше личного времени и явно отсутствие личной жизни, вот я бы для себя этого точно не хотела... (консультант, Росимущество).

В результате некоторые информантки вырабатывают приспособленческую стратегию «серого кардинала», то есть стремятся к статусу человека, обладающего реальной, но не формальной властью, которую они готовы уступить мужчинам:

...мужчины по большей части амбициозны, тщеславны, их самолюбие забивает, женщина более спокойно относится к тому, что она находится в тени, она видит вклады своей работы, и ее это устраивает (консультант, Росимущество). 
Двоякую роль играет на работе внешняя привлекательность женщины. С одной стороны, она усиливает ее восприятие как несерьезного работника, вызывает сомнения в компетентности:

...если ты симпатичная, то к тебе на первых порах немножко не очень серьезно относятся, у всех сразу подковырки: «Ммм, почему, как? Почему она заняла это место?» (главный специалист-эксперт, Государственная Дума).

С другой стороны, как отмечают информантки, внешняя привлекательность является формой власти - позволяет за счет личного обаяния неформально ускорять рабочие процессы.

Мотивация к карьерному продвижению, а не к «прозябанию» на низких должностях, сформирована у информанток наличием культурного капитала в связи с престижным образованием. Поэтому «сидеть» и «знать свое [вторичное] место» многие из них не согласны. С другой стороны, многие развивают приспособленческую стратегию и принимают условия игры: низкую зарплату и неясные перспективы повышения в обмен на гарантии декретного отпуска и крайней сложности увольнения. При этом они ценят несложную и неответственную работу, то есть в ответ на определенную дискриминацию максимально снижают интенсивность рабочих усилий и сокращают рабочее время:

Они просто хотят получать хоть какие-то деньги и не полностью сидеть дома, но как только возникают какие-то неудобства, например, человек чувствует, что он не справляется с работой, [не хотят их преодолевать] (руководитель отдела, Министерство юстиции).

Анализ показывает, что амбиции женщин, связанные с высоким уровнем образования, во многом затухают, когда работа отходит на задний план и становится своего рода дополнительной и удобной занятостью, позволяющей уделять внимание другим аспектам жизни. Это, однако, напрямую зависит от гендерных представлений о «предназначении» и «зонах ответственности» женщин и мужчин в обществе.

Баланс времени. При выборе между работой и домом женщине важно, чтобы занятость заканчивалась до шести часов вечера, оставляя время на «личную жизнь», часто сводимую к домашним обязанностям. Однако карьерно-ориентированные женщины отчасти гордятся ненормированным графиком, поскольку это создает у них ощущение востребованности, чувство, что они более «полноценные» работники, поскольку трудятся, «как мужчины». Иными словами, легитимность продвижения по службе связывается с эссенциалистскими представлениями о вторичности трудового статуса женщины и первичности мужской модели труда:

Бывали дни, когда ты не помнишь, как тебя зовут, и какое число, такой жесткий график одно время был, безумный, но ощущение, что начальник 
доверяет делать то же, что делает он сам... кто-то действительно приходит с 9 до 6, а в 6 у него заканчивается время, и он такой - a, ну, и фиг с вами, да и пошел дальше, а кто-то действительно болеет и живет этой работой (консультант, Росимущество).

Итак, структурные ограничения (продвижение на высшие руководящие должности преимущественно мужчин) тесно связаны с эссенциалистскими представлениями о вторичном статусе женщин как работниц. Это обосновывается приписываемой им повышенной эмоциональностью и низкой рациональностью, их подразумеваемой материнской и в целом репродуктивной ролью (то есть тем, что они «должны» выделять намного больше времени, чем мужчины, на ведение домашнего хозяйства и уходу за детьми, и поэтому не могут проводить на работе столько времени, сколько мужчины). Однако в случае продвижения женщины на руководящую должность «материнский» образ может использоваться и для «оправдания» ее успешной работы на этом месте. В таких условиях женщины, как правило, не стремятся открыто бороться со сложившейся ситуацией, а вырабатывают различные приспособленческие стратегии. Например, довольствуются ролью «серого кардинала», обладающего реальной, но не формальной, властью. Или присваивают некоторые «мужские» качества (готовы работать по ненормированному графику). Таким образом, женщины часто полностью принимают - по крайней мере, формально - свою «вторичную» женскую роль в трудовых отношениях, но при этом минимизируют в ответ усилия и время, затрачиваемые на труд.

\section{Заключение}

В условиях затрудненного доступа в поле и малой эмпирической изученности проблемы, исследование позволило выявить основные проблемные точки в трудовых отношениях женщин-госслужащих. Выводы ограничены в силу выборки и использованного метода, которые не позволяют экстраполировать наши результаты на всю совокупность женщин, работающих на госслужбе. На данных интервью описаны затруднения карьерного продвижения женщин-госслужащих, проинтервьюированных в рамках нашего проекта: эссенциалистские представления о своей роли на работе и профессиональных качествах, разделяемые женщинами, являются условием воспроизводства дискриминации против них; в ответ они, как правило, используют приспособленческие стратегии, например, поиск оптимального баланса времени, проводимого дома и на работе.

Несмотря на формальную возможность занимать управленческие должности, продвижение женщин по карьерной лестнице госслужбы затруднено, поскольку они вынуждены приспосабливаться к существующим предрассудкам. При этом не ставя под сомнение легитимность системы эссециалистских представлений о гендере и не рассматривая возможность 
разделения домашних обязанностей между мужчиной и женщиной. Сегодня гендерный контракт «работающая мать» (Здравомыслова, Темкина 2002) остается базовым в российском обществе, и женщины воспринимают себя как обязанных сочетать домашние обязанности и работу. В результате женщины на госслужбе вынуждены искать баланс между «женскими» и «мужскими» качествами, так как последние повышают их статус и ценность как работника, а первые «делают» их женщинами.

\section{Выражение благодарности}

Публикация подготовлена в ходе проведения исследования (проект № 18-05-0049) в рамках Программы «Научный фонд Национального исследовательского университета «Высшая школа экономики» (НИУ ВШЭ)» в 2018 г. и в рамках государственной поддержки ведущих университетов Российской Федерации «5-100».

\section{Список источников}

Ахмадеева К. (2011) «Женщины - эмоциональные, мужчины - рациональные...»: стереотипы гендера в саморефлексивном дискурсе управленцев. Вестник Казанского технологического университета, (1): 163-170.

Вебер М. (1990) Политика как призвание и профессия. Избранные произведения. М.: Прогресс: 644-706.

Здравомыслова Е., Темкина А. (2002) Советский этакратический гендерный порядок. Н. Л. Пушкарева (ред.) Социальная история. М.: РОССПЭН: 436-464.

Исупова О.Г. (2015) Материнская карьера: дети и трудовые стратегии. Социологические исследования, (11): 100-120.

Кашина М. (2009) Женщины на российской государственной гражданской службе: феминизация и воспроизводство гендерной пирамиды. Женщина в российском обществе, (2): 13-31.

Климова А., Терехова Т. (2013) Карьера государственного служащего: проблемы управления и построения. Вопросы управления, 1 (22): 55-63.

Коннелл Р. (2015) Гендер и власть: общество, личность и гендерная политика. М.: Новое литературное обозрение.

Мальцева И., Рощин С. (2007) Гендерная сегрегащия и мобильность на российском рынке труда. М.: Издательский дом ГУ-ВШЭ.

Росстат (2016) Состав кадров государственной гражданской службы РФ по полу, ветвям власти, уровням управления на 1.10.2013. Доступно по ссылке: http://www. gks.ru/free_doc/new_site/gosudar/graf2a.htm (дата обращения: 27 февраля 2017).

Тартаковская И. (2015) Воспроизводство гендерного порядка через карьерные стратегии: попытка интерсекционального анализа. Социологические исследования, (5): 84-93. 
Тартаковская И. (2001) Мужская работа, женская работа... Рубеж, (16-17): 87-101.

Ткач О. (2007) Заводские династии в современных рыночных условиях. Человек и труд, (12): 79-81.

Федеральный закон (2004) О государственной гражданской службе Российской Федерации № 79-ФЗ от 27.07.2004.

Чирикова А. (2013) Женщина во власти и бизнесе: сравнительный анализ российских и французских практик. Сравнительная политика, 2 (12): 1-21.

Batista Medina J. (2015) Public Administrations as Gendered Organizations. The Case of Spanish Municipalities. Revista Española de Investigaciones Sociológicas, (149):3-30.

Bearfield D. (2009) Equity at the Intersection: Public Administration and the Study of Gender. Public Administration Review, 69 (3):383-386.

Guy M., Schumacher K. (2009) A Retrospective Analysis of Scholarship on Gender and Diversity in Public Administration. Annual meeting of the American Political Science Association. Toronto, Canada, 03-06 September. Available at: SSRN: http://ssrn.com/abstract $=1450768$ (accessed 3rd November 2016).

Hsieh C., Winslow E. (2006) Gender Representation in the Federal Workforce a Comparison Among Groups. Review of Public Personnel Administration, 26 (3):276-295.

Ibarra H., Carter N. M., Silva C. (2010) Why Men Still Get More Promotions than Women. Harvard Business Review, 88 (9): 80-85.

Ibarra H., Ely R., Kolb D. (2011) Taking Gender into Account: Theory and Design for Women's Leadership Development Programs. Academy of Management Learning \& Education, 10 (3): 474-493.

Lindlof T., Taylor B. (2002) Qualitative Communication Research Methods. Thousand Oaks, CA: Sage. 
Olga Isupova, Valeriya Utkina

\title{
YOUNG WOMEN IN RUSSIAN PUBLIC ADMINISTRATION: THE FACTORS DETERMINING CAREER PATHS
}

\begin{abstract}
Main concern of our study is the position of women in organisations within the Russian Federation's system of government. Women are concentrated in low paid and low status positions carrying out routine work without being involved in decision making. Our research is based on thirty-two semistructured interviews with young women having experience of work in state administration. Interviews were subject to qualitative text analysis in order to discover the main themes that are important to this group of women in relation to their jobs. This article is concerned with the ideas they form on the issue of whether state administration is more of a 'feminine' or 'masculine' sphere of work, and why women here do not occupy the highest positions. On the one hand, continuing stereotypical division of labour was revealed: feminine work meant being an assistant, organising things, or more intellectual analytical or PR individual work. Masculine, in contrast, was about power and very high levels of responsibility. On the other hand, some counterstereotypical ideas were expressed. The studied group of women is characterized by a high self-esteem and aspiration to intellectual and professional self-realisation. Accordingly, women in Russian state administration, as a rule, do not aspire to the highest positions, but express aspirations for a professional career as an expert. They are not satisfied with routine work and low salaries and, as a result, try to find positions with higher salaries or better conditions. This might be associated with their high educational levels, which creates high career expectations and self-esteem. Lack of aspiration towards the highest positions of power might be associated with the perceived incompatibility of such positions with socially stereotypical 'woman's personal life', which is considered to be more time-consuming than that of a man.
\end{abstract}

Key words: public administration, women in government, gender studies, second generation gender bias

DOI: 10.17323/727-0634-2018-16-3-473-486

Olga G. Isupova - PhD in Sociology, Associate Professor, Institute of Demography, Department of Demography; Senior Research Fellow, Institute of Demography, Center for Demographical Studies, National Research University 'Higher School of Economics', Moscow, Russian Federation. Email: oisupova@hse.ru

Valeriya V. Utkina - Senior Lecturer, Faculty of Social Sciences, School of Public Administration, National Research University 'Higher School of Economics', Moscow, Russian Federation. Email: utkinavv@hse.ru 


\section{References}

Akhmadeeva K. (2011) 'Zhenshchiny - emotsional'nye, muzhchiny - ratsional'nye...': stereotipy gendera v samorefleksivnom diskurse upravlentsev ['Women are Emotional, Men are Rational...': Gender Stereotypes in Managers' Self-Reflecting Discourse]. Vestnik Kazanskogo tekhnologicheskogo universiteta [Herald of Kazan Tecnological University], (1): 163-170.

Batista Medina J. (2015) Public Administrations as Gendered Organizations. The Case of Spanish Municipalities. Revista Española de Investigaciones Sociológicas, (149):3-30.

Bearfield D. (2009) Equity at the Intersection: Public Administration and the Study of Gender. Public Administration Review, 69 (3): 383-386.

Chirikova A. (2013) Zhenshchina vo vlasti i biznese: sravnitel'nyy analiz rossiyskikh i frantsuzskikh praktik [Woman in Government and Business: Comparative Analysis of Russian and French Practices]. Sravnitel'naya politika [Comparative Politics], 2 (12): 1-21.

Connell R. (1987) Gender i vlast': obshchestvo, lichnost' i gendernaya politika [Gender and Power. Society, the Person and Sexual Politics]. Moscow: Novoe literaturnoe obozrenie.

Federal'ny Zakon (2004) O gosudarstvennoy grazhdanskoy sluzhbe Rossiyskoy Federatsii [On State Civil Service in the Russian Federation] N 79-FZ from 27.07.2004.

Guy M., Schumacher K. (2009) A Retrospective Analysis of Scholarship on Gender and Diversity in Public Administration. Annual Meeting of the American Political Science Association. Canada.

Hsieh C., Winslow E. (2006) Gender Representation in the Federal Workforce: A Comparison among Groups. Review of Public Personnel Administration, 26 (3): 276-295.

Ibarra H., Carter N.M., Silva C. (2010) Why Men Still Get More Promotions than Women. Harvard Business Review, 88 (9):80-85.

Ibarra H., Ely R., Kolb D. (2011) Taking Gender into Account: Theory and Design for Women's Leadership Development Programs. Academy of Management Learning \& Education, 10 (3): 474-493.

Isupova O. G. (2015) Materinskaya kar'yera: deti i trudovyye strategii [Maternal Career: Children and Labour Strategies]. Sotsiologicheskiye issledovaniya [Sociological Research], (11): 100-120.

Kashina M. (2009) Zhenshchiny na rossiyskoy gosudarstvennoy grazhdanskoy sluzhbe: feminizatsiya i vosproizvodstvo gendernoy piramidy [Women in the Civil Service of Russia: Feminisation and Reproduction of Gender Pyramid]. Zhenshchina v rossiyskom obshchestve [Woman in Russian Society], (2): 13-31.

Klimova A., Terekhova T. (2013) Kar'era gosudarstvennogo sluzhashchego: problemy upravleniya i postroeniya [Career of a Civil Servant: Problems of Management and Building]. Voprosy upravleniya [Management Issues], 1 (22): 55-63.

Lindlof T., Taylor B. (2002) Qualitative Communication Research Methods. Thousand Oaks, CA: Sage.

Mal'tseva I., Roshchin S. (2007) Gendernaya segregatsiya i mobil'nost' na rossiyskom rynke truda [Gender Segregation and Labor Mobility in Russian Labour Market]. Moscow: SU-HSE Publishing House.

Rosstat (2016) Sostav kadrov gosudarstvennoy grazhdanskoy sluzhby RF po polu, vetvyam vlasti, urovnyam upravleniya na 1.10.2013 [Analysis of Personnel of Civil Service of the Russian Federation by Gender, Branch and Level of Management by 1.10.2013]. Available at: http://www.gks.ru/ free_doc/new_site/gosudar/graf2a.htm (accessed 27 February 2017).

Tartakovskaya I. (2001) Muzhskaya rabota, zhenskaya rabota... [Men's Job, Women's Job]. Rubezh [The Edge], (16-17): 87-101.

Tartakovskaya I. (2015) Vosproizvodstvo gendernogo poryadka cherez kar'ernye strategii: popytka intersektsional'nogo analiza [The Gender Order Reproduction Via Career Strategies: Intersectional Analyses]. Sotsiologicheskie issledovaniya [Sociological Studies], (5): 84-93.

Tkach O. (2007) Zavodskie dinastii v sovremennykh rynochnykh usloviyakh [Factory Dynasties in Modern Market Conditions]. Chelovek i trud [Man and Work], (12): 79-81.

Weber M. (1990) Politika kak prizvanie i professiya [Politics as a Vacation]. Izbrannye proizvedeniya [Selected Writings]. Moscow: Progress: 644-706.

Zdravomyslova E., Temkina A. (2003) Sovetskiy etakraticheskiy gendernyy poryadok [Soveit Etactatic Gender Order]. In: N. L. Pushkareva (ed.) Social'naja istorija. Ezhegodnik - 2003 [Social History Yearbook 2003]. Moscow: ROSSPEN: 436-464. 